\title{
Infectious aortitis: A bridge too far
}

In the book A Bridge Too Far by Cornelius Ryan, ${ }^{1}$ British Lt Gen Frederick Browning told the field commander Bernard Montgomery, "We may be going a bridge too far," in reference to Operation Market Garden, which, ultimately, failed as the Allied powers attempted to break through German lines at Arnhem across the Rhine river during World War II.

As we all accept, infectious aortitis remains a very difficult problem with poor outcomes. We acknowledge that the use of thoracic endovascular aortic repair is a temporizing "bridge" to the eventual, more definitive, approach of open repair.

Infectious aortitis was first introduced by Osler in 1885 as a sequel of infective endocarditis and named mycotic endarteritis. ${ }^{2}$ The term, "infectious aortitis," or infected aneurysm, is now commonly used. It encompasses infection of the arterial wall caused by septic emboli, contiguous spread from adjacent structures, and hematogenous dissemination. ${ }^{3}$ This infection often occurs in the pre-existing aneurysms or atherosclerotic lesions and, thus, infectious aortitis is more often seen in the abdominal aorta than the thoracic aorta. Non-typhi Salmonella is the leading causative organism for mycotic aneurysms. ${ }^{4}$ Non-typhi Salmonella gastroenteritis is observed worldwide, with 93.8 million cases per year, ${ }^{5}$ causing bacteremia in about $10 \%$ of these patients. ${ }^{6}$ Endothelial infection after Salmonella bacteremia may occur in $9 \%,{ }^{7}$ with an increased rate with age. ${ }^{4,7}$ Hence, the chance to encounter the Salmonella aortitis is not insignificant.

A recent study published from Sweden demonstrated that $60 \%$ of infectious aortitis is now treated with endovascular repair, with superior early outcomes compared with open surgery, but the superiority diminishes in midterm. ${ }^{8}$ Endovascular repair of infectious aortitis leaves the concern for recurrent or persistent infection in $20 \%$ to $24 \%,{ }^{8,9}$ which often leads to death within 6 months.

Nonetheless, infectious complications after an open repair still occur. Local infection control with radical debridement followed by long-term antibiotics is the key to treating infectious aortitis, and graft material (homograft

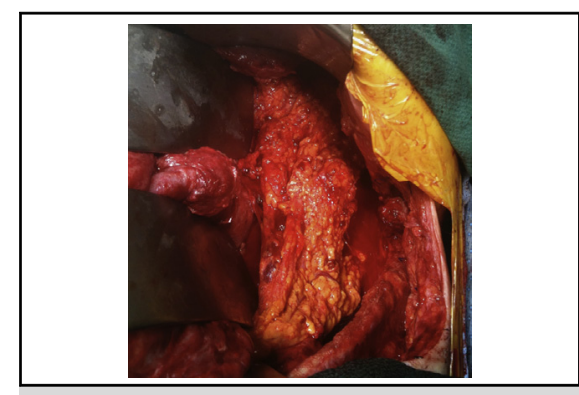

An intraoperative photograph of infectious aortitis repaired with omentum coverage.

\section{Central Message}

Endovascular repair is an effective bridge for ruptured, unstable, infectious aortitis, but radical resection of infected tissues is ultimately required to obtain respectable longterm outcomes.

See Article page e87.

vs rifampicin-impregnated Dacron [INVISTA Sarl, Kennesaw, Ga], polytetrafluoroethylene, or simple Dacron) should only be considered as an augmentation of the treatment. We should not fully depend on homograft to overcome the infectious aortitis. If complete debridement of the affected arterial walls and surrounding infected tissues is not possible, the risk of reinfection increases. In such cases, we prefer the use of local tissue flaps (ie, omentum, latissimus dorsi muscle, etc) to cover the graft and the affected aorta (Central Figure).

We congratulate Dr Brewer and colleagues ${ }^{10}$ for a successful "bridging" for a patient with a ruptured Salmonella aortitis. Thoracic endovascular aortic repair was effectively used as a bridge therapy to stabilize to hemodynamics and provided sufficient time for systemic antibiotic therapy before definitive treatment with open repair, via a homograft. The patient was discharged home with 6 weeks of antibiotic therapy but, unfortunately, died in a motor vehicle collision. Although the details of the patient's death were unknown, it remains uncertain whether an aortic catastrophe could have led to the motor vehicle collision.

At any rate, infectious aortitis remains a challenging surgical problem. Aside from the established principles of removal of infected prosthetic material, wide-local excision of infected tissues, and long-term antibiotics, many more questions remain unresolved: Which is more durable, anatomic or extra-anatomical bypass? Autogenous or artificial conduit? Impregnated versus nonimpregnated grafts? 
Pedicle coverage or not? Timing of intervention-sooner or later? Antibiotic coverage-life-long or time-specific?

These are just some of the many questions that must be answered. Until that time-and until we achieve improved long-term survival-the chapter of infectious aortitis remains unwritten, and the bridge is still too far.

\section{References}

1. Ryan C. A Bridge Too Far. 1st ed. New York: Simon \& Schuster Inc; 1974

2. Osler W. The Gulstonian Lectures, on Malignant Endocarditis. Br Med J. 1885; 1: 467-70.

3. Hiratzka LF, Bakris GL, Beckman JA, Bersin RM, Carr VF, Casey DE Jr, et al. 2010 ACCF/AHA/AATS/ACR/ASA/SCA/SCAI/SIR/STS/SVM guidelines for the diagnosis and management of patients with Thoracic Aortic Disease: a report of the American College of Cardiology Foundation/American Heart Association Task Force on Practice Guidelines, American Association for Thoracic Surgery, American College of Radiology, American Stroke Association, Society of Cardiovascular Anesthesiologists, Society for Cardiovascular Angiography and
Interventions, Society of Interventional Radiology, Society of Thoracic Surgeons, and Society for Vascular Medicine. Circulation. 2010;121:e266-369.

4. Wang JH, Liu YC, Yen MY, Wang JH, Chen YS, Wann SR, et al. Mycotic aneurysm due to non-typhi salmonella: report of 16 cases. Clin Infect Dis. 1996;23: 743-7.

5. Majowicz SE, Musto J, Scallan E, Angulo FJ, Kirk M, O’Brien SJ, et al. The global burden of nontyphoidal Salmonella gastroenteritis. Clin Infect Dis. 2010;50:882-9.

6. Black PH, Kunz LJ, Swartz MN. Salmonellosis - a review of some unusual aspects. N Engl J Med. 1960;262:811-7.

7. Cohen PS, O'Brien TF, Schoenbaum SC, Medeiros AA. The risk of endothelial infection in adults with salmonella bacteremia. Ann Intern Med. 1978;89:931-2.

8. Sorelius K, Wanhainen A, Furebring M, Bjorck M, Gillgren P, Mani K, et al. Nationwide study of the treatment of mycotic abdominal aortic aneurysms comparing open and endovascular repair. Circulation. 2016;134:1822-32.

9. Luo CM, Chan CY, Chen YS, Wang SS, Chi NH, Wu IH. Long-term outcome of endovascular treatment for mycotic aortic aneurysm. Eur J Vasc Endovasc Surg. 2017:54:464-71.

10. Brewer ZE, Dake MD, Fischbein MP. Two-stage surgical approach for ruptured Salmonella aortitis. J Thoracic Cardiovasc Surg. 2018;155:e87-9. 